Cite this: Phys. Chem. Chem. Phys., 2011, 13, 15891-15898

\title{
Novel self-assembling system based on resorcinarene and cationic surfactant $\dagger$
}

\author{
Ruslan R. Kashapov, ${ }^{a b}$ Tatiana N. Pashirova, ${ }^{a}$ Sergey V. Kharlamov, ${ }^{a}$ \\ Albina Yu. Ziganshina, ${ }^{a}$ Elena P. Ziltsova, ${ }^{a}$ Svetlana S. Lukashenko, ${ }^{a}$ \\ Lucia Ya. Zakharova, ${ }^{a b}$ Wolf D. Habicher, ${ }^{c}$ Shamil K. Latypov ${ }^{a}$ and \\ Alexander I. Konovalov ${ }^{a}$
}

Received 24th March 2011, Accepted 24th June 2011

DOI: $10.1039 / \mathrm{c} 1 \mathrm{cp20906j}$

Mixed association of calix[4]resorcinarene with ethyl sulfonate groups on the lower rim and dimethylaminomethyl groups on the upper rim (CR) and cationic surfactant 4-aza-1-hexadecylazoniabicyclo[2.2.2]octane bromide (DABCO-16) is studied by methods of tensiometry, conductometry, potentiometry and NMR spectroscopy at fixed CR concentration and varied surfactant concentration. Beyond $c a .0 .4 \mathrm{mM}$ of DABCO-16, mixed aggregates enriched by $\mathrm{CR}$ are proved to be formed due to electrostatic forces, while beyond $c a .5 \mathrm{mM}$, aggregates enriched by surfactant occur due to the hydrophobic effect. Spectrophotometry monitoring of the solubilization of a hydrophobic dye, Orange OT, demonstrated that only the second type of mixed aggregate enriched by DABCO-16 is capable of binding the organic probe, while the mixed system where the surfactant is a minor component shows no binding capacity towards Orange OT. This finding can be used for the design of nanocontainers with controllable binding/release properties.

\section{Introduction}

Supramolecular systems (and constituent building blocks) belong to biomimetic species, which model at least two essential features of their biological prototypes, i.e. the capacity to associate spontaneously and to interact through the "guest-host" mechanism. ${ }^{1-5}$ These peculiarities, mainly resulting from non-covalent bonds, predetermine the wide application of supramolecular systems in nano- and biotechnologies. The design of supramolecular soft materials, i.e. nanocontainers, catalysts, sensors, drug and gene delivery systems are well documented. ${ }^{6-15}$ Our researches focus on two key biomimetic building blocks, namely supramolecular systems based on surfactants and cyclophanes (calixarenes and pyrimidinophanes), which are capable of binding practically important organic substrates. Applications of these systems as receptors, nanocontainers and nanoreactors ${ }^{16-27}$

${ }^{a}$ A. E. Arbuzov Institute of Organic and Physical Chemistry of the Russian Academy of Sciences, 8 Arbuzov Str., Kazan 420088, Russia.E-mail: lucia@iopc.ru; Fax: 7843 2732253;

Tel: 78432732293

${ }^{b}$ Kazan State Technological University, 68 Karl Marx Str., Kazan 420015, Russia

${ }^{c}$ Technical University, Bergstr. 66c D-01062 Dresden, Germany

$\dagger$ Electronic supplementary information (ESI) available: Description of the NMR self-diffusion procedure, calculations of binding constants, and plots on self-diffusion coefficients and the $\Delta E$ values. See DOI: $10.1039 / \mathrm{clcp} 20906 \mathrm{j}$ are based on two different mechanisms of self-organization and guest-host interactions. Surfactants are typical selforganizing systems, whose association in aqueous solution is mainly contributed by the hydrophobic effect and results in small micelles formed at a definite concentration, denoted as the critical micelle concentration $(\mathrm{cmc})$. Micelles can bind a diversity of substrates via solubilization mechanisms, with binding constants being markedly controlled by the hydrophilic-lipophilic balance of the solutes. At the same time the specific aggregation mode of cyclophane based amphiphiles is quite different from that of conventional surfactants, ${ }^{28-41}$ and the association processes seem to involve electrostatic, $\mathrm{CH}-\pi$ and inclusive interactions in this case. Calixarenes typically form inclusion complexes, which demonstrate a highly selective ability to bind the substrates, thereby controlling the chemical and geometrical guest-host affinity. Therefore, a promising way to design supramolecular soft matter is the combination of the two aforementioned building blocks, which opens the way to enlarge the variety of mechanisms involved in the self-organization and binding of the substrates. In addition, owing to their biomimetic character, supramolecular systems may provide information on the separate factors controlling the behavior of biological systems, which can hardly be revealed in vivo.

A few works are available on the mixed surfactant-calixarene systems, which are mainly focused on the catalytic activity. ${ }^{4-47}$ Our goal is to achieve a better understanding of the factors, 


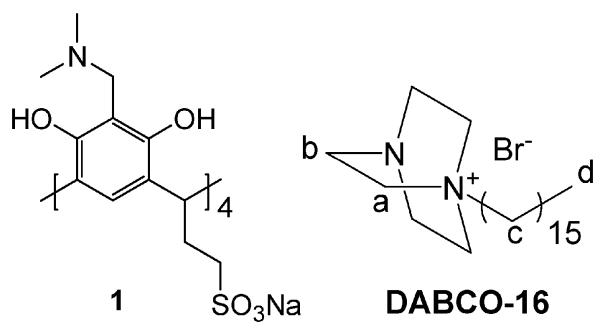

Scheme 1 Structural formulas of calix[4]resorcinarene 1 and DAB$\mathrm{CO}-16$; in the DABCO-16 molecule, protons of bicyclic skeleton are marked as 'a' (at a charged nitrogen) and 'b' (at uncharged nitrogen), while aliphatic protons are marked as 'c' (in methylene moieties) and 'd' (in a terminal methyl group).

which control the mixed solution behavior, including such aspects as variation of aggregative capacity, aggregate properties, as well as the stoichiometry, the strength and the nature of interactions in the case when mixed assembling is realized. Two building blocks are explored, i.e. cationic surfactant 4-aza1-hexadecyl-azoniabicyclo[2.2.2] octane bromide (DABCO-16) and calix[4]resorcinarene sulfonatoalkylated at the lower rim and aminoalkylated at the upper rim (1) (Scheme 1). Non-alkylated DABCO is widely explored in design of supramolecular catalytic systems, supramolecular architectures, photochromic materials, etc. ${ }^{48-50}$ Self-organization of alkylated DABCOs is earlier shown to depend on their hydrophobicity and results in the formation of both isotropic systems, i.e. micellar aggregates of different size and shape, and liquid crystalline mesophases. ${ }^{51-53}$ Calix[4]resorcinarene (CR) $\mathbf{1}$ is documented $^{54}$ to associate through a head-to-tail pattern owing to electrostatic interactions between positively charged amino groups and negatively charged sulfonato groups. These interactions and their binding capacity are markedly determined by solution $\mathrm{pH}$, which controls the amino group protonation and hence the presence of charge at the upper rim.

\section{Experimental}

Synthesis of DABCO-16 and $\mathbf{1}$ were described elsewhere. ${ }^{51,54}$

All NMR experiments were performed on a Bruker AVANCE-600 spectrometer operating at $600.13 \mathrm{MHz}$ for the ${ }^{1} \mathrm{H}$. The spectrometer was equipped with a Bruker multinuclear $z$-gradient inverse probe head capable of producing gradients with strength of $53.5 \mathrm{G} \mathrm{cm}^{-1}$. All experiments were carried out at $25 \pm 0.2{ }^{\circ} \mathrm{C}$. Chemical shifts were reported relative to HDO (4.7 ppm) as an internal standard. Experimental details are given in the electronic supporting material $\dagger$ and in ref. 55 and 56.

Electrical conductivities were measured using an InoLab Cond 720 precision conductivity meter with a graphite electrode having a cell constant of $0.475 \mathrm{~cm}^{-1} \pm 1.5 \%$. The conductance of different solutions was measured on addition of an aliquot of a known concentration of a surfactant or resorcinarene solution to a given volume of the thermostated doubly distilled water. Reproducibility was checked for selected samples and no significant differences were observed. All samples were studied at $25 \pm 0.1{ }^{\circ} \mathrm{C}$.
Surface tension measurements were performed using the du Nouy ring detachment method. The experimental details are described elsewhere. ${ }^{57}$

Electromotive force measurements using an ion-selective electrode are well suited for the determination of the ionic species activity. The Nernst equation is known to describe the relation between the electrode potential $(\Delta E)$ and the activity of bromide ion $\left(a_{\mathrm{Br}}\right)$ :

$$
\Delta E=-\frac{R T}{F} \log \left(a_{\mathrm{Br}}\right)+\text { const }
$$

where $F$ is the Faraday constant and the ideal slope $(R T / F)$ is $59.2 \mathrm{mV}$ /equiv at $298.2 \mathrm{~K}^{58}$ The measurements were performed for the counterion $\left(\mathrm{Br}^{-}\right)$using ion meter I-160MI, with a Br-selective electrode ELIS-131Br and a reference electrode ESr-10101/3.0. The electromotive force $(\Delta E)$ of the cell was measured for the sample solutions with a stepwise increasing concentration, where the temperature of the sample was kept constant at $25^{\circ} \mathrm{C}$. For this cell, the Nernst equation was valid over the concentration range from $10^{-6}$ to $10^{-1} \mathrm{M}$ whenever $\mathrm{KBr}$ was used as a solute. The degree of counterion binding to aggregates, $\beta$, being the ratio of counterions and amphiphile ions in the micelles, can be calculated from the mass balance for surfactant ion and counterion at any total concentration $C_{\mathrm{t}}$ using the following expression:

$$
\beta=\frac{\left(C_{\mathrm{t}}-\left[\mathrm{Br}^{-}\right]\right)}{\left(C_{\mathrm{t}}-\mathrm{cmc}\right)}
$$

1-(o-Tolyl-azo)-2-naphthol (Orange OT, Aldrich) was used as received. The solubilization experiments were performed by adding an excess of crystalline dye to solutions. These solutions were allowed to equilibrate for about $48 \mathrm{~h}$ at room temperature. They were filtered, and their absorbency was measured at $495 \mathrm{~nm}$ (molar extinction coefficient $17400 \mathrm{~L} \mathrm{~mol}^{-1} \mathrm{~cm}^{-1}$ ) using SP-26 spectrophotometer. Quartz cuvettes containing the sample were used, with a cell length of $0.1 \mathrm{~cm}$.

\section{Results and discussion}

\subsection{Single solutions}

The cmc value of individual DABCO-16 is around $1 \mathrm{mM} \cdot{ }^{51-53}$ As for $\mathrm{CR}$, depending on the $\mathrm{pH}$ different forms of $\mathbf{1}$ occur in the solution. ${ }^{54}$ Within the framework of this study, spontaneous solution $\mathrm{pH}$ around $9.0 \pm 0.2$ was maintained due to acid-base interactions of amino groups at the upper rim with water. Amino groups are slightly protonated, while sulfonato groups at the lower rim are completely dissociated under these conditions, so that the resorcinarene $\mathbf{1}$ is negatively charged and self-associated within $0-0.005 \mathrm{M}$ solution. ${ }^{54}$

Herein the self-organization of the single aqueous solution of $\mathbf{1}$ was monitored within a wide concentration range. A decrease in the surface tension at the air/aqueous solution interface occurs with the $\mathrm{CR}$ concentration (Fig. 1), i.e. 1 exhibits the surface activity. In analogy with typical surfactants, the decrease in surface tension occurs before the cmc. We failed to reach a pronounced plateau because of the limited solubility ( $\leq 0.03 \mathrm{M}$ ) of $\mathbf{1}$ in water. At the same time, a smooth decrease in the surface tension above the $\mathrm{cmc}$ can result from 


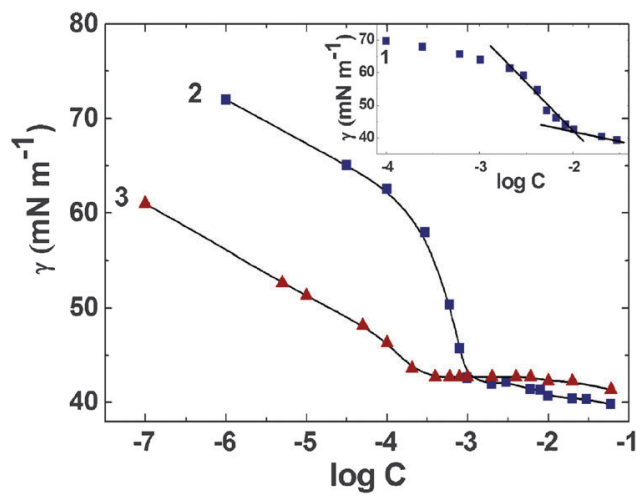

Fig. 1 Surface tension isotherms of single solutions of 1 (1) (Inset), DABCO-16 (2) and mixed 1-DABCO-16 system at fixed CR concen-

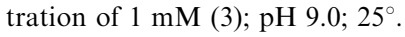

the fact that the composition of the air-water interface does not remain constant when the surfactant concentration increases. The breakpoint is also evident from the specific conductivity versus concentration plot for the single CR aqueous solution (Fig. 2). Experimental points below and above the breakpoint were linearized in the 'conductivity' versus 'concentration' coordinates (Fig. 1S $\dagger$ ), and the $\mathrm{cmc}$ value was derived from the solution of the system of equations. According to tensiometry and conductometry data, the cmc is equal to 0.009 and $0.013 \mathrm{M}$, respectively. To gain insight into the self-organization process in more detail, NMR self-diffusion coefficient (D) measurements were invoked. Unfortunately due to fast exchange on the NMR self-diffusion time scale between free and associated sites, the experimentally observed $D_{\text {obs }}$ is a mole fraction weighted average of contributions from these forms: ${ }^{59,60}$

$$
D_{\text {obs }}=X_{\text {free }} D_{\text {free }}+X_{\text {mic }} D_{\text {mic }}
$$

where the symbols $X_{\text {free }}$ and $D_{\text {free }}$ refer to the mole fraction and self-diffusion coefficient of the amphiphile monomer, while the symbols $X_{\text {mic }}$ and $D_{\text {mic }}$ refer to the mole fraction and self-diffusion coefficient of the micelles.

According to NMR experiments, an increase in the concentration results in a decrease in $D_{\text {obs }}$ (Fig. 3), indicating the association of 1 with the cmc value equal to $5 \mathrm{mM}$ in this case

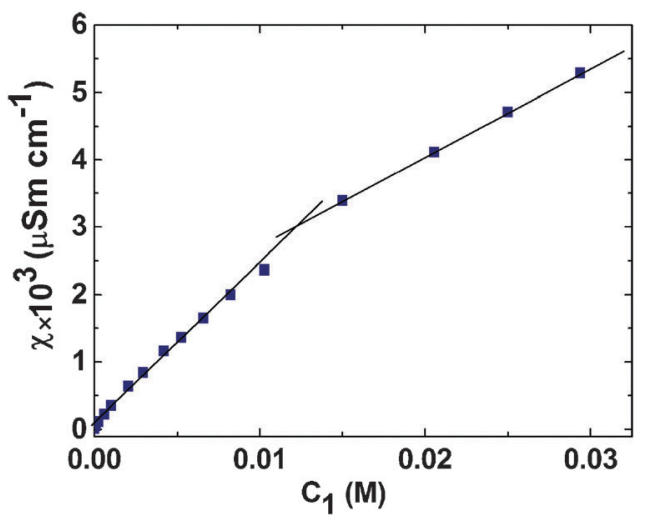

Fig. 2 Dependence of the specific conductivity of the single 1 solution on the concentration of CR; $\mathrm{pH} 9.0 ; 25^{\circ}$.

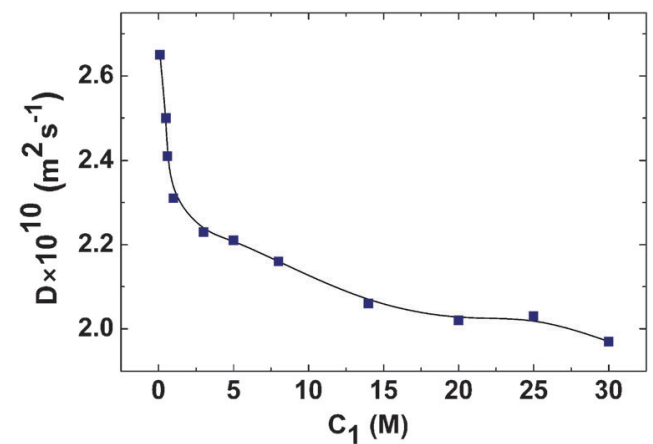

Fig. 3 Dependence of self-diffusion coefficients of 1 on its concentration; $\mathrm{pH} 9.0 ; 25^{\circ} \mathrm{C}$.

Table 1 Cmc values of single and mixed systems based on 1 and DABCO-16

\begin{tabular}{|c|c|c|c|c|}
\hline \multirow[b]{2}{*}{ System } & \multicolumn{4}{|l|}{$\mathrm{Cmc} / \mathrm{mM}$} \\
\hline & Tensiometry & Conductometry & Potentiometry & NMR \\
\hline DABCO-16 & 1.0 & 1.0 & 1.9 & $0.8^{44}$ \\
\hline 1 & 9.0 & 13 & - & 5 \\
\hline DABCO-16-1 ${ }^{a}$ & 0.4 & $0.1(7)$ & $0.2^{c}$ & 0.45 \\
\hline DABCO-16-1 ${ }^{b}$ & - & $0.5(22)$ & - & - \\
\hline \multicolumn{5}{|c|}{$\begin{array}{l}{ }^{a} C_{\mathbf{1}}=1 \mathrm{mM} \cdot{ }^{b} C_{1}=5 \mathrm{mM} \cdot{ }^{c} \text { Values have only apparent significance } \\
\text { owing to the low concentration range preventing the precise } \\
\text { measurements. }\end{array}$} \\
\hline
\end{tabular}

(Fig. $2 \mathrm{~S}, \dagger$ Table 1). It should be noted that some differences may be observed in the data obtained in $\mathrm{D}_{2} \mathrm{O}$ and $\mathrm{H}_{2} \mathrm{O}$. The stronger hydrogen bonding in $\mathrm{D}_{2} \mathrm{O}$ can result in a lower cmc value and a larger micelle size. ${ }^{61,62}$ However, the differences in cmc usually do not exceed $30 \%$. We believe that this discrepancy is not dramatic and does not prevent insight into the structural behavior of the systems studied.

\subsection{Binary 1-DABCO-16 solutions}

Since 1 bears large negative charge at the lower rim, it seemed interesting to study its mixed association with the cationic surfactant, e.g. DABCO-16. Both components self-assemble on their own, but in quite different manners. The self-aggregation of the calixarene is proposed to occur in a head-to-tail fashion. ${ }^{54}$ Cationic surfactant form micelles above the cmc. There are different ways to study the association in binary systems. The first way proposes the variation of total surfactant concentration, while the second way involves the variation of the concentration of one component at the fixed concentration of another. Initially we proposed to explore both ways. However, we failed to investigate the whole concentration range using the first method owing to precipitation of the mixed complex. Similar precipitation was also observed in a single resorcinarene 1 solution at $\mathrm{pH}<4,{ }^{54}$ when amino groups at the upper rim are positively charged. This indicates that the precipitation is probably due to the stoichiometry electrostatic interactions, which prevail over cooperative association. The second way is attractive from the viewpoint of transition between the two different modes of association typical for each component. This method provides an instrument for the 
formation of nanocontainers with controllable binding/release properties due to their concentration-dependent behavior.

Fig. 1 shows the surface tension isotherm for the binary system at a fixed concentration of $\mathbf{1}$. The surface tension versus DABCO-16 concentration plot is very similar to those for typical surfactants and demonstrates a breakpoint at the concentration of $0.4 \mathrm{mM}$. This value is markedly lower in comparison to the $\mathrm{cmc}$ of the single DABCO-16 solution (Table 1), and this is in full agreement with the assumption that mixed 1-DABCO-16 aggregates are formed. The specific conductivity versus surfactant concentration plot is shown in Fig. $4 \mathrm{a}$ and $\mathrm{b}$. The following features should be mentioned. (i) The absolute values of conductivity are lower in comparison to the single 1 solution within the whole concentration range, but are much higher than in the DABCO-16 single solution, ${ }^{51,52}$ lying around $100 \mu \mathrm{Sm} \mathrm{cm}^{-1}$ beyond the $\mathrm{cmc}$ (for comparison those for cetyltrimethylammonium bromide are about $150 \mu \mathrm{Sm} \mathrm{cm}^{-1}$ ).

These conductivities are determined by the values of $\mathrm{cmc}$ and degree of counterion binding. Undoubtedly, the high level of the conductivity in a single CR solution (Fig. 2) results from the occurrence of four anionic sulfonato groups at the lower rim and the high cmc value of $\mathbf{1}$. The modules of conductivity values in the mixed 1-DABCO-16 system are mainly controlled by the fixed CR concentration of $1 \mathrm{mM}$ or $5 \mathrm{mM}$. (ii) It should be emphasized that the curve 3 in Fig. 1 describe the behavior of the mixed system under the varied component ratio. In the case of conductivity measurements we monitor the overall changes of the number of charged species resulted
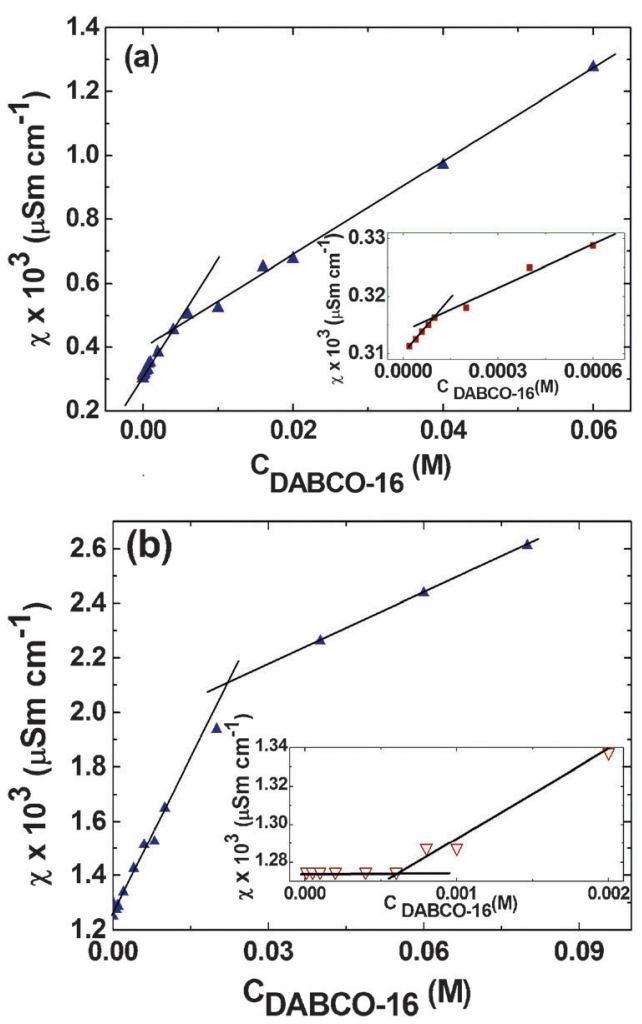

Fig. 4 Dependence of specific conductivity of the mixed 1-DABCO-16 system at fixed CR concentration of 1 (a) and 5 (b) $\mathrm{mM}$; $\mathrm{pH} 9.0 ; 25^{\circ}$. The inset elucidates a low concentration range. from both their aggregation and their interaction with each other. Therefore within the concentration range below the tensiometry cmc of $0.4 \mathrm{mM}$, ionic components (negatively charged CR and positively charged DABCO-16) would interact electrostatically, thus resulting in charge compensation. As a result, the conductivity of the mixed system changes only slightly (Fig. 4a, inset) or remains constant (Fig. 4b, inset) in this concentration range. For this reason the breakpoint in the conductivity versus concentration plots depends on the CR concentration and the cmc value derived from these data would differ from the tensiometry value. In particular, cmc of 0.1 and $0.5 \mathrm{mM}$ are determined for the case of 1 and $5 \mathrm{mM}$ fixed CR concentration respectively (insets in Fig. $4 a$ and b). It is noteworthy that breakpoints are observed at the $10: 1$ CR/DABCO-16 molar ratio in both cases. This probably indicates that mixed associative complexes formed at the initial stage are enriched by CR and demonstrate sharp decrease in the mixed cmc in comparison with both $\mathbf{1}$ and DABCO-16. This may be caused by the above charge compensation, because cmc values of nonionic amphiphiles are known to be lower in comparison to ionic ones. (iii) Above the cmc, the mixed solution behavior is mainly contributed by hydrophobic effect. As can be seen from Fig. 4a and b, the conductometry dependences show additional breakpoints in the range of higher concentration, i.e. beyond 6 or $22 \mathrm{mM}$, depending on the $\mathrm{CR}$ concentration. This provides evidences for the structural rearrangement of aggregates, in particular transition to the micelles enriched by DABCO-16.

Fig. 5 and 6 and $3 \mathrm{~S} \uparrow$ show potentiometry data for the single DABCO-16 solution and 1-DABCO-16 binary system. The potentiometric study using a Br-selective electrode is focused on the evaluation of the degree of counterion binding. However, the analysis of the $\left[\mathrm{Br}^{-}\right]$versus [surfactant] and $\Delta E$ versus $\left[\mathrm{Br}^{-}\right]$dependences may provide deeper insight into the aggregation behavior of the system. Breakpoints in the $\left[\mathrm{Br}^{-}\right]$ versus [surfactant] plot typically reflect the onset of micellization or structural transitions. As can be seen from Fig. 5, Inset, there is a discontinuity around the tensiometry cmc. However, one should be aware that due to the low $\mathrm{cmc}$ value of the system experimental values below the cmc may be inaccurate owing to a limitation of the method. The same breakpoint is

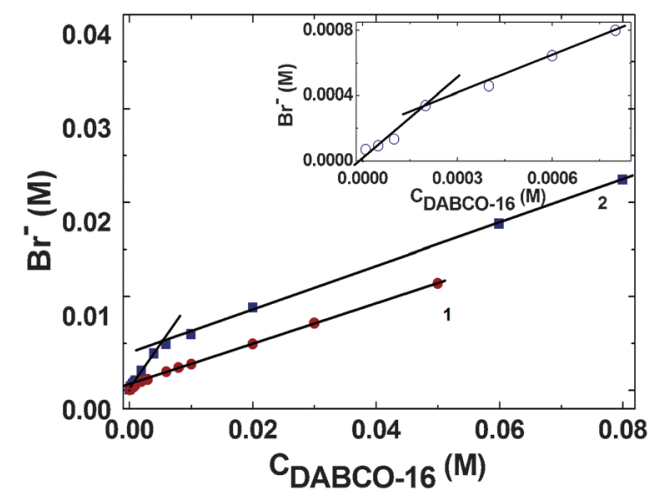

Fig. 5 The concentration of free bromide-ions versus surfactant concentration in single DABCO-16 solution (1) and mixed 1-DABCO-16 system (2); $1 \mathrm{mM} \mathrm{1;} \mathrm{pH} 9.0 ; 25^{\circ}$. The inset elucidates a low concentration range. 


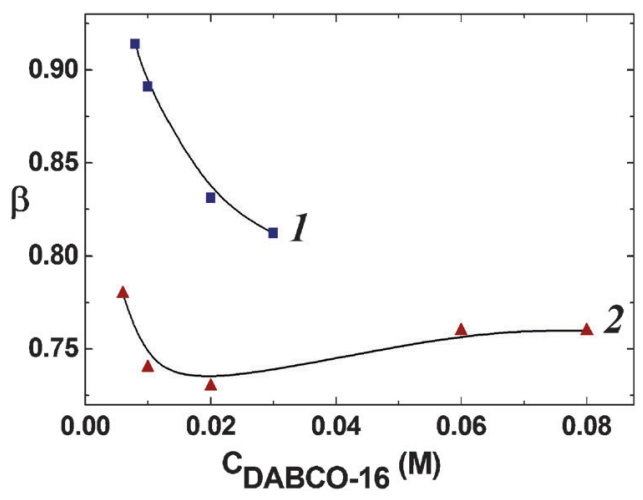

Fig. 6 Dependence of degree of counterion binding on the DABCO-16 concentration for single DABCO-16 solution (1) and mixed 1-DABCO-16

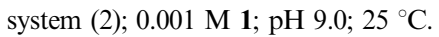

evident from Fig. $3 \mathrm{~S} \dagger$ depicting the potential of Br-selective electrode as a function of the bromide-ion concentration.

It is of importance that we fail to estimate the counterion (i.e. bromide-ion) binding within the low surfactant concentration. This is probably due to the above mentioned electrostatic interactions between DABCO-16 cationic groups and sulfonato-anions of $\mathbf{1}$. The competition between hydrophilic bromide-anions and four-charged anions attached to highly hydrophobic platform seems to offer advantages to the latter due to its lower affinity to aqueous phase. Therefore, even at the concentration exceeding the tensiometry $\mathrm{cmc}$, total dissociation of bromide-ions occurs. This observation is supported by the slope of $\Delta E v s .\left[\mathrm{Br}^{-}\right]$plot equals $56.7 \mathrm{mV} /$ equiv, which is close to the ideal Nernst slope of 59.2 typical for strong electrolytes like $\mathrm{KBr}$ (Fig. $3 \mathrm{~S} \dagger$ ). It is reasonable to assume that the breakpoint in the $\left[\mathrm{Br}^{-}\right] v s$. [surfactant] plot (Fig. 5) at the $\sim 4 \mathrm{mM}$ indicates the onset of binding of bromide-ions with micelles. This value is very close to the conductivity breakpoint at $6 \mathrm{mM}$ (Fig. 4a), indicating the formation of the micelles enriched by DABCO- 16 .

The degree of counterion binding is plotted in Fig. 6. A decrease in $\beta$ occurs in the mixed system as compared to single DABCO-16 solution. This is probably due to the aforementioned competition between $\mathrm{Br}^{-}$and CR-anions. Besides, the charge compensation prior to the cmc imparts nonionic character to associated species, so that ionic head groups are alternated with nonionic ones. This typically provides conditions for lowering the counterion binding.

The 1-DABCO-16 system was also studied by NMR titration method and the efficiency of the guest-host interactions was estimated. As a whole, the changes in chemical shift (CS) of DABCO-16 protons (Fig. 7) with concentration of the 1-DABCO-16 complex are small (less than $-0.2 \mathrm{ppm}$ ), although according to NMR diffusivity data (vide infra) aggregation takes place. Thus one can conclude that the DABCO-16 binds outside the cavity since otherwise the upfield shift should be observed for the guest protons due to a shielding effect of the host aromatic rings. ${ }^{18,41,63-67}$ Moreover marked upfield shifts are observed only for protons of the DABCO-16 bicyclic skeleton, i.e. for protons which are vicinal to the positively charged head group. Upon these observations one can offer a hypothesis that the association is driven

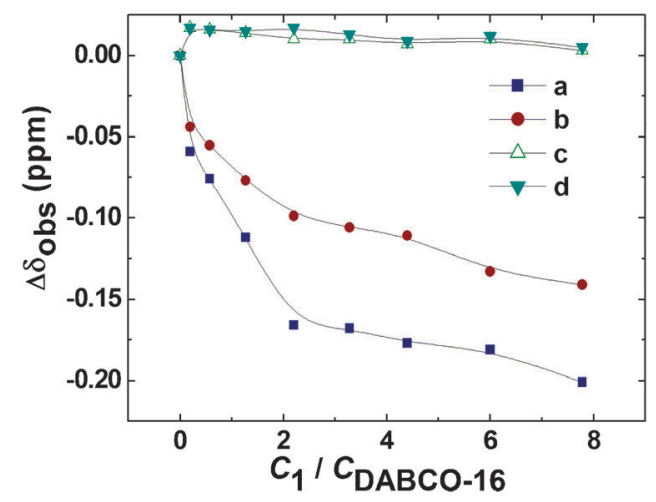

Fig. 7 Dependence of changes in chemical shifts of protons of DABCO-16 (DABCO-16 proton designations are given in Scheme 1) on the 1/DABCO-16 molar ratio. Initial concentrations are: $[\mathrm{DABCO}-16]=0.0007 \mathrm{M} ;[\mathbf{1}]=0.007 \mathrm{M}$.

by electrostatic interactions between sulfonato groups of the lower rim of $\mathrm{CR}$ and cationic head groups of the surfactant.

To obtain further information, the interaction of 1 with non-alkylated DABCO was also studied (Fig. 8 and 9). The titration Job plot shows 1:1 stoichiometry of the 1-DABCO complex and the binding constant between components equals 350. Unfortunately, we failed to determine the stoichiometry of the 1-DABCO-16 complex by the Job method, since at the needed concentration range $(\geq 0.001 \mathrm{M})$ the precipitation occurs. However, if one assumes that stoichiometry of 1-DABCO-16 is $1: 1$, then the binding constant of the complex changes to 3500 , which is tenfold higher than for the complex with non-alkylated DABCO. An increase in the binding constant for the case of DABCO-16 is probably due to the contribution of electrostatic attractive interactions with the participation of the positively charged $\mathrm{N}$ atom.

Self-diffusion coefficients of the binary 1-DABCO-16 system are measured to provide deeper insight into the mixed behavior. Fixed concentration of $1(1 \mathrm{mM})$ was used, while the concentration of DABCO-16 was varied (Fig. 10). The particular attention was paid to the concentration range before the tensiometry $\mathrm{cmc}$ of $0.4 \mathrm{mM}$. It was found that (i) the self-diffusion coefficient of $\mathbf{1}\left(D_{1}\right)$ at fixed concentration of $1 \mathrm{mM}$ is lower than that of the monomeric form, i.e. the association of $\mathbf{1}$ is initiated. A decrease of $D_{\mathbf{1}}$ with the increase

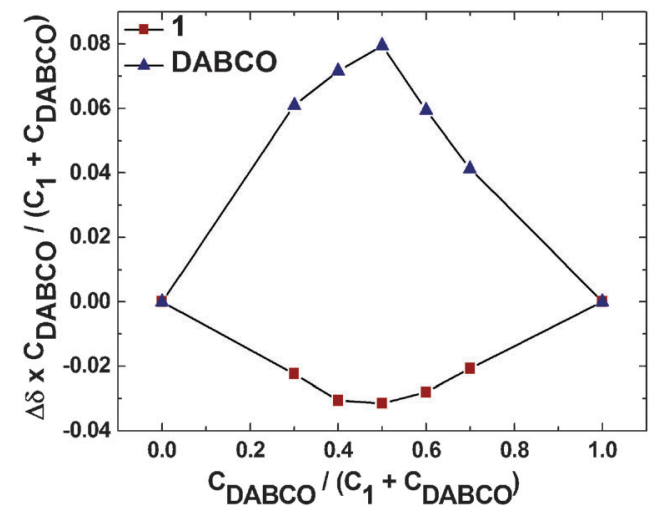

Fig. 8 Job plots for the signals of $\mathrm{DABCO}$ protons and aromatic protons of $\mathrm{CR}$ in $\mathbf{1}+\mathrm{DABCO}$ solution $\left[\mathrm{C}_{\mathbf{1}}+\mathrm{C}_{\mathrm{DABCO}}=0.01 \mathrm{M}\right]$. 


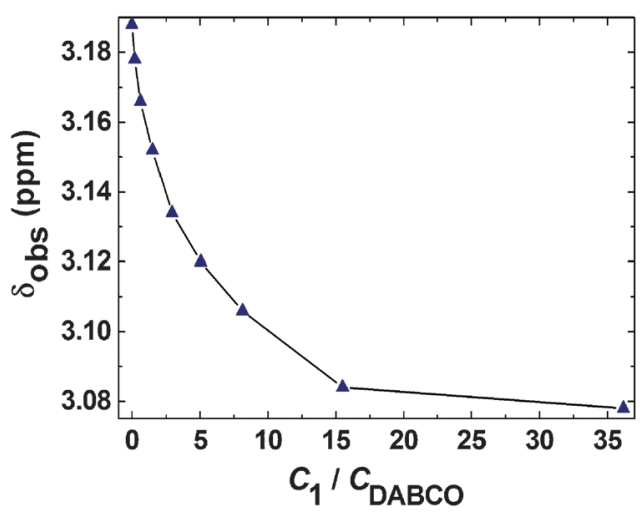

Fig. 9 Plots of the current induced shift for the signal of DABCO protons as a function of $\mathrm{C}_{\mathbf{1}} / \mathrm{C}_{\mathrm{DABCO}}$.

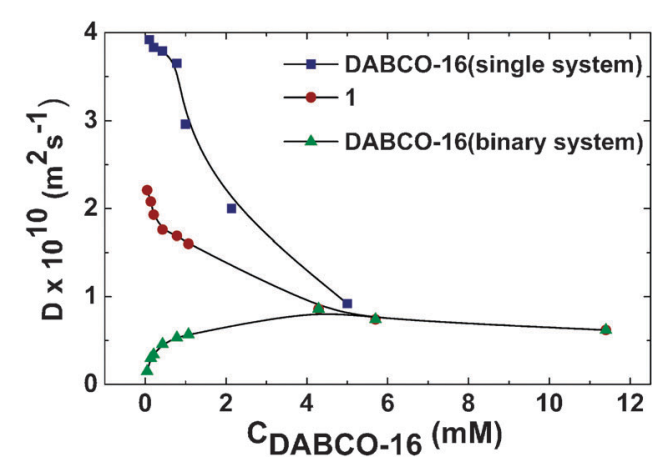

Fig. 10 Self-diffusion coefficients of the components of $1+$ DABCO-16 solution $\left(C_{\mathrm{DABCO}}\right.$ is varying, $\left.\mathrm{C}_{\mathbf{1}}=1 \mathrm{mM}\right)$ and DABCO-16 in individual solution; $\mathrm{D}_{2} \mathrm{O} ; 25^{\circ} \mathrm{C}$.

of DABCO-16 concentration occurs, which can be explained by the formation of 1-DABCO-16 aggregates with larger hydrodynamic radius and by an increase in their mole fraction with the surfactant concentration. (ii) Even within concentration range before the tensiometry $\mathrm{cmc}$ the self-diffusion coefficient of DABCO-16 ( $\left.D_{\mathrm{DABCO}-16}\right)$ is significantly lower (ca. $0.1 \times 10^{-10} \mathrm{~m}^{2} \mathrm{~s}^{-1}$ ) in comparison to its aggregated form in single surfactant solution. This is probably due to the involving of the DABCO-16 molecules into the $\mathbf{1}$ aggregates with large hydrodynamic radius through electrostatic interaction between cationic head groups and sulfonato groups of CR. An unusual increase in the self-diffusion coefficients of DABCO-16 occurs with surfactant concentration (Fig. 10). It can originate from the fact that the molar ratio of $\mathbf{1}$ with respect to DABCO-16 decreases with surfactant concentration, and therefore impact of 1-DABCO-16 aggregates also becomes smaller. In other words the mole fraction of the fast component (monomeric DABCO-16) increases. It is noteworthy that the range of pronounced changes in self-diffusion coefficients of both components (a decrease for $\mathbf{1}$ and increase for DABCO-16) does not go beyond the point of $0.4 \mathrm{mM}$, whereupon a smoother behavior occurs. Another critical point is $c a .5 \mathrm{mM}$, in which the values of self-diffusion coefficients of CR coincide with those of aggregated DABCO-16 in both single surfactant solution and binary system. In order to clarify the observed structural behavior and quantify the degree of binding of the CR molecules to the 1-DABCO-16 aggregates within the two-site "bound-free" model the coefficient $K_{\mathrm{S}}=C_{\mathbf{1} \text { (bound) }} / C_{\mathrm{DABCO}}$ was introduced. Here $C_{\mathbf{1} \text { (bound) }}$ is the concentration of CR molecules, which are involved into the aggregates (see $\mathrm{SI} \dagger$ ). Thus the physical meaning of $K_{\mathrm{S}}$ is a mean value of $\mathrm{CR}$ aggregated molecules per one molecule of DABCO-16. The plot of $K_{\mathrm{S}}$ as a function of $C_{\mathrm{DABCO}-16}$ (Fig. 11) has a critical point at $c a .0 .25 \mathrm{mM}$, which is close to the tensiometry cmc. Before this point $K_{\mathrm{S}}$ varies only slightly and markedly decreases after it. It looks like that within the concentration range of $0-0.25 \mathrm{mM}$ the efficiency of the 1-DABCO-16 aggregation is rather high, so the number of $\mathrm{CR}$ molecules per one aggregate is almost constant, i.e. the stoichiometry of the aggregates is also constant. This means that within the above concentration range, an increase in the DABCO-16 concentration does not result in the enriching of the mixed aggregates by DABCO-16 molecules. So, an increase in the portion of the unbound DABCO-16 molecules is observed with total surfactant concentration. After the critical point of $0.25 \mathrm{mM}$, the molar fraction of the calixarenefree DABCO-16 molecules becomes too high, so $K_{\mathrm{S}}$ decreases. In this concentration range the transition occurs from the CR-host aggregates to the DABCO-16-host aggregates. At high concentration $D_{\mathrm{DABCO}-16}$ is probably a weighted average between another two states: DABCO-16 micelles $\left(D \sim 0.5 \times 10^{-10} \mathrm{~m}^{2} \mathrm{~s}^{-1}\right)$ and 1-DABCO-16 aggregates $\left(D \sim 0.1 \times 10^{-10} \mathrm{~m}^{2} \mathrm{~s}^{-1}\right)$, therefore some decrease of $D_{\mathrm{DABCO}}$ occurs in the concentration range $>4 \mathrm{mM}$ (Fig. 10).

To elucidate the nature of aggregates formed at the different 1-DABCO-16 ratio, a highly hydrophobic probe Orange OT was used. It is insoluble in water, while can be solubilized by nonpolar interior of direct micelles occuring above $\mathrm{cmc}$ in aqueous surfactant solutions. This is reflected by the appearance of absorbancy in the visible range of spectrum around $500 \mathrm{~nm}$. This phenomenon is widely used for monitoring the micellization of amphiphilic compounds. ${ }^{68,69}$ Fig. 12 shows the absorbancy versus concentration dependences derived from the dye solubilization measurements in single DABCO-16 and 1 solutions and the mixed 1-DABCO-16 system. The cmc value for single DABCO-16 found from these data is equal to $1 \mathrm{mM}$ (Fig. 12). This value is similar to $\mathrm{cmc}$ of the single DABCO-16 determined by tensiometry and conductometry. Almost linear increase in the amount of solubilized Orange OT is observed within the concentration interval limited by $\mathrm{cmc}$ and concentration of $5 \mathrm{mM}$ (Fig. 12). This probably indicates

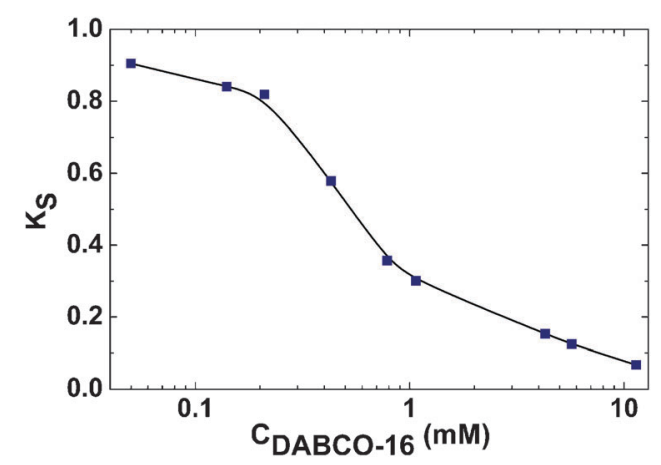

Fig. 11 Dependence of the degree of binding of 1 to the $1+$ DABCO-16 aggregates on DABCO-16 concentration. 


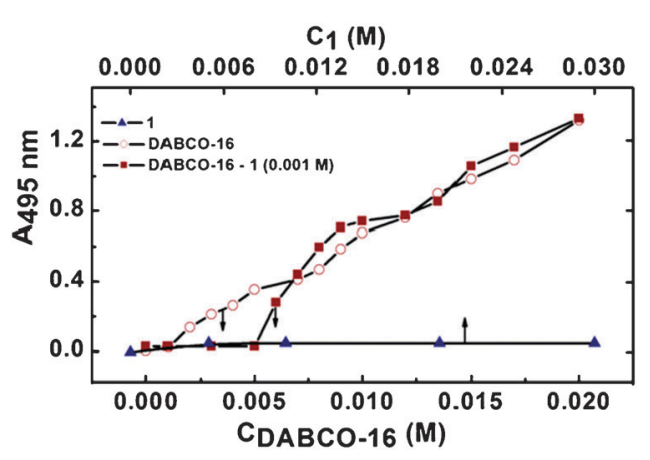

Fig. 12 Dependence of optical density at $495 \mathrm{~nm}$ on DABCO-16 concentration in the absence and presence of $\mathbf{1}$ (lower scale) and on $\mathbf{1}$ concentration (upper scale); $25^{\circ}$; optical length $0.1 \mathrm{~cm}$.

an unchanged morphology of self-organized assemblies in this concentration range. Some decrease in the dye absorption observed above $5 \mathrm{mM}$ reflects a decrease in the solubilization capacity of the DABCO-16 micelles and can be due to the changes in the form of aggregates. For single 1 solutions no absorbancy was observed throughout the whole concentration range from $1 \mathrm{mM}$ to $30 \mathrm{mM}$ corresponding to the solubility limit of the macrocycle (Fig. 12). Such behavior provides strong arguments in favour of the fact that morphology of the 1-based aggregates differs markedly from that of typical surfactants, in particular DABCO-16. This difference may be used for design of nanocontainers with controllable binding capacity towards guests. The binding-release behavior of guests can be governed by the variation of the 1-DABCO-16 ratio (Scheme 2). This assumption was supported by the dye solubilization study in the mixed 1-DABCO-16 system (Fig. 12). As can be seen, the dye absorbancy at $495 \mathrm{~nm}$ appears only at the surfactant concentration of $5 \mathrm{mM}$. This concentration corresponds to the formation of mixed micelles enriched by DABCO-16. These data strongly support the above assumption on the occurrence of two different types of mixed aggregates, i.e. aggregates with the surfactant as a minor component and aggregates with the resorcinarene as a minor species. The former occur above $0.4 \mathrm{mM}$ and demonstrate no solubilization capacity, while the latter occur above $5 \mathrm{mM}$ and can bind hydrophobic guests through solubilization mechanism. This result is of importance from the viewpoint of the problem of drug delivery formulations.

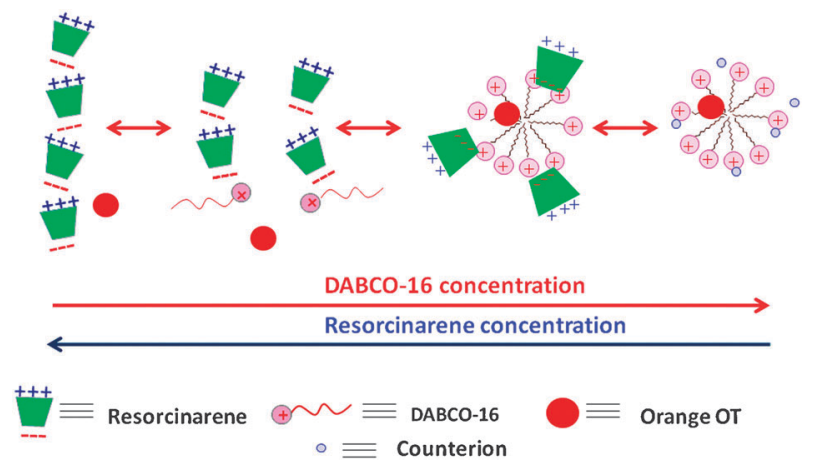

Scheme 2 Changes in the supramolecular architecture with the variation in the DABCO-16-1 ratio: the controllable guest release.

\section{Conclusions}

The self-organization in the binary system based on the cationic surfactant 4-aza-1-hexadecyl-azoniabicyclo[2.2.2]octane bromide and calix[4]resorcinarene sulfonatoalkylated at the lower rim and aminoalkylated at the upper rim has been studied. The interplay of different methods allowed us to get insight into the structural behavior of the title system. We assume that two different associative modes are realized in the binary system under the fixed CR concentration and varied surfactant concentration. A surface tension versus DABCO-16 concentration plot demonstrates a breakpoint at $0.4 \mathrm{mM}$, which is lower in comparison to single DABCO-16 cmc of $1 \mathrm{mM}$ and single CR $\mathrm{cmc}$ of $c a .10 \mathrm{mM}$. The close values of the breakpoints are revealed by a variety of methods: conductometry, potentiometry and NMR self-diffusion. Small changes in the conductivity and potential data and the compensating changes in self-diffusion coefficients, i.e. a decrease for $\mathrm{CR}$ and increase for DABCO-16 indicate the mixed associative process mainly controlled by the electrostatic mechanism. Mixed aggregates enriched by the CR molecules are assumed to be formed at the first stage of the association. Second breakpoint is observed under the higher surfactant concentration of $c a .5 \mathrm{mM}$, which is assumed to indicate the formation of mixed micelles enriched by DABCO-16 molecules through conventional surfactant aggregation mode mainly contributed by hydrophobic effect. The solubilization study with the use of hydrophobic dye Orange OT demonstrated that only mixed aggregates enriched by DABCO-16 are capable of binding the organic probe, while mixed system where the surfactant is a minor component shows no binding capacity towards Orange OT. This finding can be used for the design of nanocontainers with controllable binding-release properties.

\section{Acknowledgements}

We thank the Russian Foundation for Basic Researches (Grants 10-03-90416-Ukr_a, 09-03-00123, 09-03-00581) for financial support. R. R. K. thanks the Deutscher Akademischer Austauschdienst (DAAD) foundation (grant A/09/ 83380) for financial support. This investigation was carried out in the NMR Department (A. E. Arbuzov Institute of Organic \& Physical Chemistry) of the Federal collective spectral analysis center for physical and chemical investigations of structure, properties and composition of matter and materials.

\section{References}

1 I. W. Hamley and V. Castelletto, Angew. Chem., Int. Ed., 2007, 46, 4442.

2 J. H. Fendler, Chem. Rev., 1987, 87, 877.

3 N. B. Bowden, M. Weck, I. S. Choi and G. M. Whitesides, Acc. Chem. Res., 2001, 34, 231.

4 J. A. Zasadzinski, E. Kisak and C. Evans, Curr. Opin. Colloid Interface Sci., 2001, 6, 85.

5 S. Mann, Angew. Chem., Int. Ed., 2008, 47, 5306.

6 K. Holmberg, Curr. Opin. Colloid Interface Sci., 2003, 8, 187.

7 T. Dwars, E. Paetzold and G. Oehme, Angew. Chem., Int. Ed., 2005, 44, 7174.

8 M. A. Mintzer and E. E. Simanek, Chem. Rev., 2009, 109, 259. 
9 W. Y. Shi, S. He, M. Wei, D. G. Evans and X. Duan, Adv. Funct. Mater., 2010, 20, 3856.

10 S. Matile, A. Vargas Jentzsch, A. Fin and J. Montenegro, Chem. Soc. Rev., 2011, 40, 2453.

11 S. Liu and Z. Tang, J. Mater. Chem., 2010, 20, 24.

12 K. T. Kim, S. A. Meeuwissen, R. J. M. Nolte and J. C. M. van Hest, Nanoscale, 2010, 2, 844.

13 B. Nandan, B. K. Kuila and M. Stamm, Eur. Polym. J., 2011, 47, 584 .

14 X. Zhang and C. Wang, Chem. Soc. Rev., 2011, 40, 94.

15 J. P. Rao and K. E. Geckeler, Prog. Polym. Sci., 2011, 36, 887.

16 C.-J. Jia and F. Schüth, Phys. Chem. Chem. Phys., 2011, 13, 2457.

17 F. Sansone, L. Baldini, A. Casnati and R. Ungaro, New J. Chem., $2010,34,2715$.

18 L. Onel and N. J. Buurma, Annu. Rep. Prog. Chem., Sect. B, 2010, 106, 344.

19 L. M. Salonen, M. Ellermann and F. Diederich, Angew. Chem., Int. Ed., 2011, 50, 4808.

20 D. T. Schühlea, J. A. Peters and J. Schatz, Coord. Chem. Rev. (in press).

21 L. Ya. Zakharova, V. V. Syakaev, M. A. Voronin, V. E. Semenov, F. G. Valeeva, A. R. Ibragimova, A. V. Bilalov, R. Kh. Giniyatullin, Sh. K. Latypov, V. S. Reznik and A. I. Konovalov, J. Colloid Interface Sci., 2010, 342, 119.

22 A. R. Ibragimova, G. I. Vagapova, G. A. Gainanova, V. V. Syakaev, V. M. Zakharov, I. Kh. Rizvanov, L. Ya. Zakharova, S. K. Latypov and A. I. Konovalov, Mendeleev Commun., 2011, 21, 53.

23 M. A. Voronin, D. R. Gabdrakhmanov, V. E. Semenov, F. G. Valeeva, A. S. Mikhailov, I. R. Nizameev, M. K. Kadirov, L. Ya. Zakharova, V. S. Reznik and A. I. Konovalov, ACS Appl. Mater. Interfaces, 2011, 3, 402.

24 L. Ya. Zakharova, A. B. Mirgorodskaya, E. I. Yackevich, A. V. Yurina, V. V. Syakaev, S. K. Latypov and A. I. Konovalov, J. Chem. Eng. Data, 2010, 55, 5848.

25 L. Y. Zakharova, A. B. Mirgorodskaya, E. P. Zhiltsova, L. A. Kudryavtseva and A. I. Konovalov, Organic Reactions in Constrained Systems, ed. U. H. Brinker and J. -L. Mieusset, Wiley, Chichester, 2010.

26 L. Ya. Zakharova, V. V. Syakaev, M. A. Voronin, F. V. Valeeva, A. R. Ibragimova, Y. R. Ablakova, E. Kh. Kazakova, Sh. K. Latypov and A. I. Konovalov, J. Phys. Chem. C, 2009, 113, 6182.

27 L. Ya. Zakharova, Yu. R. Kudryashova, N. M. Selivanova, M. A. Voronin, A. I. Ibragimova, S. E. Solovieva, A. T. Gubaidullin, A. I. Litvinov, I. R. Nizameev, M. K. Kadirov, Yu. G. Galyametdinov, I. S. Antipin and A. I. Konovalov, J. Membr. Sci., 2010, 364, 90-101.

28 D. M. Rudkevich, in Calixarene 2001, ed. Z. Asfari, V. Bohmer, J. Harrowfield and J. Vicens, Kluwer Academic Publishers, Dordrecht, 2001.

29 F. Corbellini, R. M. A. Knegtel, P. D. J. Grootenhuis, M. Credo-Calama and D. N. Reinhoudt, Chem.-Eur. J., 2005, 11, 298.

30 F. Corbellini, F. W. B. van Leeuwen, H. Beijleveld, H. Kooijman, A. L. Spek, W. Verboom, M. Crego-Calama and D. N. Reinhoudt, New J. Chem., 2005, 29, 243.

31 G. V. Oshovsky, D. N. Reinhoudt and W. J. Verboom, J. Am. Chem. Soc., 2006, 128, 5270.

32 S. Arimori, T. Nagasaki and S. Shinkai, J. Chem. Soc., Perkin Trans. 2, 1995, 679.

33 S. Shinkai, T. Arimura, K. Araki, H. Kawabata, H. Satoh, T. Tsubaki, O. Manabe and J. Sunamoto, J. Chem. Soc., Perkin Trans. 1, 1989, 2039.

34 F. Inokuchi and S. Shinkai, J. Chem. Soc., Perkin Trans. 2, 1996, 601.

35 S. Shinkai, S. Mori, H. Koreishi, T. Tsubaki and O. Manabe, J. Am. Chem. Soc., 1986, 108, 2409.

36 H. Mansikkamaki, M. Nissenen, C. A. Schalley and K. Rissanen, New J. Chem., 2003, 27, 88.

37 D. J. Eisler and R. J. Puddephatt, Inorg. Chem., 2005, 44, 4666.

38 M. Strobel, K. Kita-Tokarczyk, A. Taubert, C. Vebert, P. A. Heiney, M. Chami and W. Meier, Adv. Funct. Mater., 2006, 16, 252.

39 E. J. Cho, J. K. Kang, W. S. Han and J. H. Jung, Langmuir, 2008, 24, 5229.
40 S. Houmadi, D. Coquière, L. Legrand, M. C. Fauré, M. Goldmann, O. Reinaud and S. Rémita, Langmuir, 2007, 23, 4849 .

41 V. V. Syakaev, A. R. Mustafina, J. G. Elistratova, Sh. K. Latypov and A. I. Konovalov, Supramol. Chem., 2008, 20, 453.

42 I. S. Ryzhkina, K. M. Enikeev, A. P. Timosheva, S. S. Lukashenko, L. A. Kudryavtseva, A. I. Konovalov, O. N. Chupahin, G. L. Rusinov and N. A. Itsikson, Zh. Strukt. Khim., 2005, 46, 70.

43 G. A. Gainanova, E. P. Zhiltsova, L. A. Kudryavtseva, S. S. Lukashenko, A. P. Timosheva and A. I. Konovalov, Izv. AN Ser. khim., 2007, 5, 918.

44 L. Y. Zakharova, A. R. Mustafina, F. V. Valeeva, A. R. Ibragimova, Y. R. Ablakova, J. G. Elistratova, V. V. Syakaev, L. A. Kudryavtseva and A. I. Konovalov, Kolloid. Zh., 2008, 4, 485.

45 E. P. Zhiltsova, Y. I. Abdyusheva, S. S. Lukashenko, E. M. Kasymova, A. R. Kayupov, A. R. Burilov, A. P. Timosheva and A. I. Konovalov, Zh. Obshch. Khim., 2009, 79, 294.

46 A. R. Mustafina, L. Ya. Zakharova, J. G. Elistratova, M. A. Voronin, V. V. Syakaev and A. I. Konovalov, J. Colloid Interface Sci., 2009, 333, 613-618.

47 A. Mustafina, L. Zakharova, J. Elistratova, J. Kudryashova, S. Soloveva, A. Garusov, I. Antipin and A. Konovalov, J. Colloid Interface Sci., 2010, 346, 405-413.

48 K. E. Price, S. J. Broadwater, H. M. Jung and D. T. McQuade, Org. Lett., 2005, 7, 147-150.

49 J. H. Li, J. L. Li, D. P. Wang, S. F. Pi, Y. X. Xie, M. B. Zhang and X. C. Hu, J. Org. Chem., 2007, 72, 2053-2057.

50 P. Ballester, A. I. Oliva, A. Costa, P. M. Deya, A. Frontera, R. M. Gomila and C. A. Hunter, J. Am. Chem. Soc., 2006, 128, $5560-5569$.

51 T. N. Pashirova, E. P. Zhiltsova, R. R. Kashapov, S. S. Lukashenko, L. Ya. Zakharova and A. I. Konovalov, Izv. AN Ser. Khim., 2010, 9, 1699-1706.

52 N. K. Gaisin, O. I. Gnezdilov, T. N. Pashirova, E. P. Zhiltsova, S. S. Lukashenko, L. Ya. Zakharova, V. V. Osipova, V. I. Dzhabarov and Yu. G. Galyametdinov, Kolloid. Zh., 2010, 6, 755-761.

53 L. Ya. Zakharova, T. N. Pashirova, R. R. Kashapov, E. P. Zhiltsova, N. K. Gaisin, O. I. Gnezdilov, A. B. Konov, S. S. Lukashenko and I. M. Magdeev, Kinet. Katal., 2011, 2.

54 D. E. Korshin, R. R. Kashapov, L. I. Murtazina, R. K. Mukhitova, S. V. Kharlamov, Sh. K. Latypov, I. S. Ryzhkina, A. Y. Ziganshina and A. I. Konovalov, New J. Chem., 2009, 33, 2397-2401.

55 D. Wu, A. Chen and C. S. Johnson, J. Magn. Reson., Ser. A, 1995, $115,260-264$

56 J. Garcia de la Torre, M. L. Huertas and B. Carrasco, J. Magn. Reson., 2000, 147, 138-146.

57 L. Zakharova, F. Valeeva, A. Zakharov, A. Ibragimova, L. Kudryavtseva and H. Harlampidi, J. Colloid Interface Sci., 2003, 263, 597.

58 R. A. Robinson and R. H. Stokes, Electrolyte Solutions, Butterworth, London, 1970.

59 M. Jansson and P. Stilbs, J. Phys. Chem., 1987, 91, 113-116.

60 M. Jansson and P. Stilbs, J. Phys. Chem., 1985, 89, 4868-4873.

61 N. J. Chang and E. W. Kaler, J. Phys. Chem., 1985, 89, 2996-3000.

62 T. Ozawa, T. Asakawa, V. M. Garamus, A. Ohta and Sh. Niyagishi, J. Oleo Sci., 2005, 54, 585-588.

$63 \mathrm{H}$. Gunther, NMR Spectroscopy: An Introduction, Wiley, New York, 1980, p. 450.

64 C. W. Haigh and R. B. Mallion, Prog. Nucl. Magn. Reson. Spectrosc., 1979, 13, 303-344.

65 Sh. K. Latypov, J. M. Seco, E. Quinoa and R. Riguera, J. Org. Chem., 1995, 60, 504-515.

66 M. Demura, T. Yoshida, T. Hirokawa, Y. Kumaki, T. Aizawa, K. Nitta, I. Bitter and K. Tothd, Bioorg. Med. Chem. Lett., 2005, 15, $1367-1370$.

67 G. S. Ananchenko, K. A. Udachin, M. Pojarova, A. Dubes, J. A. Ripmeester, S. Jebors and A. W. Coleman, Cryst. Growth Des., 2006, 6, 2141-2148.

68 H. Schott, J. Phys. Chem., 1967, 71, 3611-3617.

69 P. Venkatesan, Y. Cheng and D. Kahne, J. Am. Chem. Soc., 1994, 116, 6955-6956. 